\title{
Delayed triggering of oestrogen induced apoptosis that contrasts with rapid paclitaxel-induced breast cancer cell death
}

I Obiorah, S Sengupta, P Fan and V C Jordan

Correction to: British Journal of Cancer (2014) 110, 1488-1496. The authors and publishers apologise for this mistake. doi:10.1038/bjc.2014.50

One of the authors of the above paper had identified that Figure 7 was not reproduced correctly from their original flow data. The correct figure has been reproduced below. 


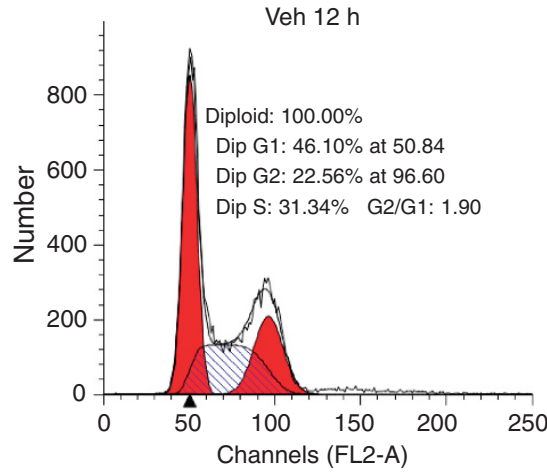

Veh $24 \mathrm{~h}$

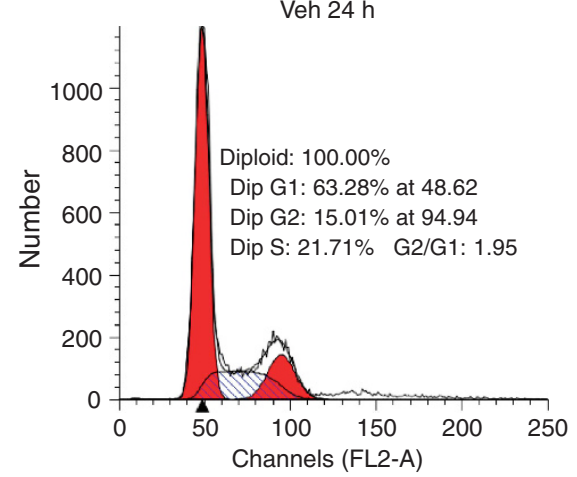

Veh $48 \mathrm{~h}$

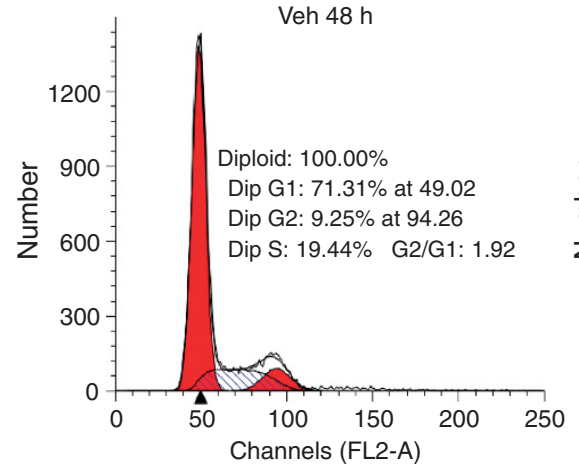

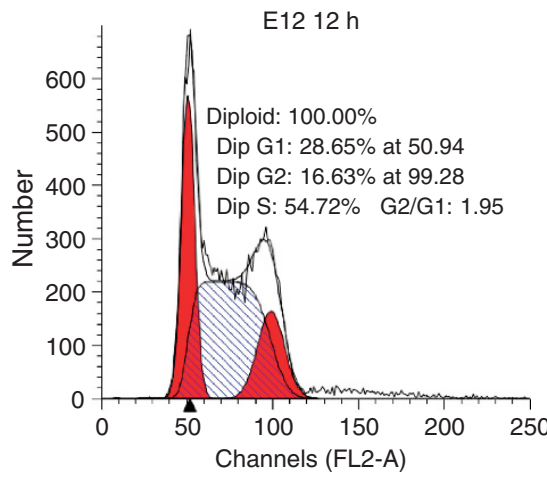

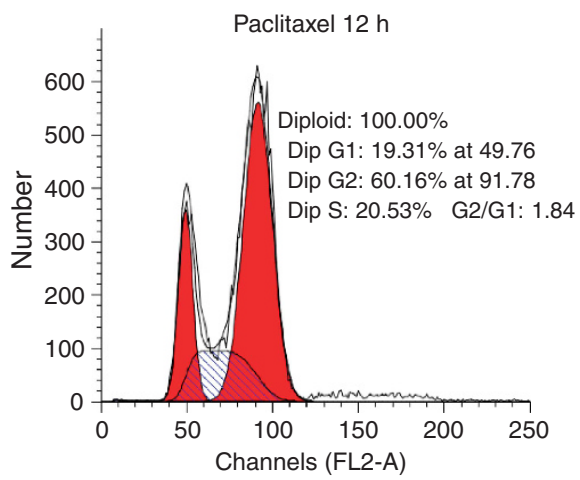

E2 $24 \mathrm{~h}$
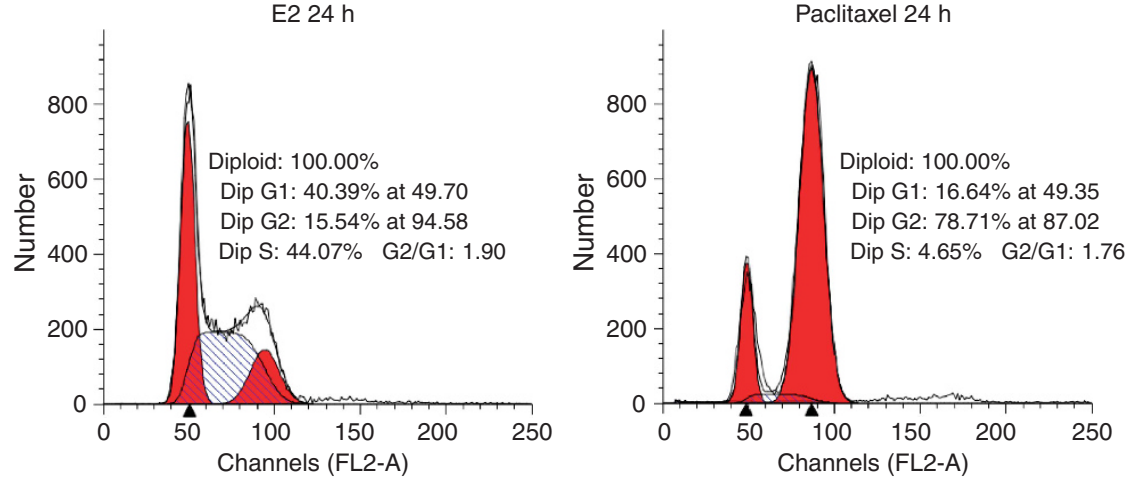

E2 $48 \mathrm{~h}$

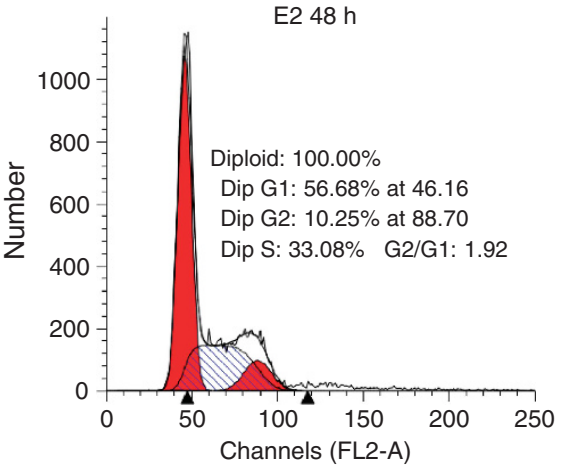

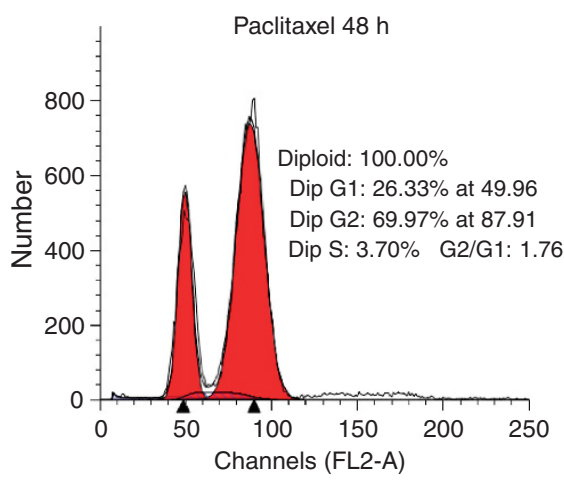

Figure 7. Cell cycle analysis of the effects of $E_{2}$ and paclitaxel in the MCF7:5C cells. Representative cell cycle profiles of MCF7:5C cells treated with either $0.1 \%$ ethanol (Veh), $E_{2}(1 \mathrm{nM})$ or paclitaxel $(1 \mu \mathrm{M})$ for 12,24 and $48 \mathrm{~h}$. FL2-A represents the intensity of Pl, and the $y$-axis represents the cell number. 